\title{
Postmodern Perspective of Yi's New Year
}

\author{
Jijiang Zhao \\ Southwest Nationalities Research Academy, Southwest University for Nationalities, Chengdu \\ 610041, Sichuan, China. \\ jijiang2012@163.com
}

\begin{abstract}
Through retelling the Yi's New Year myth and analyzing the rituals presenting in the festival, this thesis has made a rediscovery about the myth and its social values in a postmodern perspective and found that the Yi's New Year myth is the spiritual source and homeland of Yi people, which include a huge amount of wisdom concerning survival and contain the belief of protecting intangible cultural heritage.
\end{abstract}

Keywords: Postmodern perspective; retelling myth; Yi's New Year; Ritual; Social value.

\section{后现代视野中的彝族新年神话}

\section{赵积将}

\section{西南民族大学西南民族研究院 成都 中国}

摘 要: 本文通过对彝族新年神话的重述以及对新年期间的各种仪式活动的表述, 重新认识了 在后现代的神话语境中的彝族新年神话及其社会价值, 认为新年神话是彝族社会重要的的精 神根源和灵魂家园、蕴含着大量生存的智慧、包含非物质文化遗产保护的理念。

关键词：后现代视野；重述神话；幽族新年；仪式；社会价值

\section{1. 前言}

从20世纪到 21 世纪初逐步形成了一种运用后现代的理论来重新叙述与理解神话的趋势, 这使神话有复兴的迹象, 也是新神话主义的理论源头。神话作为人类启蒙智慧的表达, 是人 类文化的基因与文、史、哲等学科的起源。在2005年英国坎农伯格出版公司策动了重述神话 的国际出版项目, 选择各国的精英作者对本民族神话题材进行再挖掘和再创造, 形成全球发 行的小说 (翻译为各国语言)。较早出版的《神话简史》成了重述神话的理论总纲, 突出了 后现代视野对神话的新认识，对理解20世纪后期以来新神话主义运动有指导作用。[1]

\section{2. 后现代视野中神话的特征及其定义}

后现代视野中神话的特征: 一是重新发掘被传统科学知识所长期压抑的边缘社会中形形 色色的口耳相传的神话与史诗。二是尊重和关注文化多样性。后现代视野不仅把神话视为一 种文学艺术的形式, 而且要更多地从人类学、心理学、宗教学等角度展开论述。后现代视野 中神话的描述性定义: 神话是对死亡及其意义的追问, 是超理性的思考与想象, 是与现存世 界并存的另一维度 (神的世界)。神话的作用是叫凡人得以模仿神并体验神性, 是人类经验 的汇总, 为人提供解脱困境之道, 有助于发现自己在世界的位置及具备适应世界的能力。[2] 后现代视野中的神话是神话传说在人类社会中的流传与演变的过程, 包括传说与文本, 相关 的仪式及活动, 参与者的心理及态度, 对社会的影响等多个方面。也指具有原始文化内涵的 神话思维、神圣叙事和生活规范。[3,4] 


\section{3. 后现代视野中的彝族新年神话}

彝族是一个具有悠久历史与灿烂文化的民族, 主要聚居在中国西南部的滇川黔桂四省, 其余散居于境内外。彝族年是彝族的重要节日，一般在农历十月左右。以下从后现代的视野 分别探讨彝族新年神话及其仪式。

\section{1 重述彝族年神话传说}

在很久很久以前, 有一座美丽的大山, 山下有肥沃的土地, 山上有茂盛的树林, 在这里 愉快的生活着的有一户彝族人家, 在山上还有各种小动物, 例如老鼠、青蛙、蟒蛇、乌鸦、 云雀、花狗等。这里一年四季就像春天一样, 既没有大雨也没有大雪, 太阳每天早上从东边 山顶升起，下午又从西边的山顶落下，年复一年，日复一日。山下还有一个很大的湖泊，湖 水很清, 可以看见里面的鱼儿在自由地游泳, 青蛙在湖里呱呱的叫着。

这一年又到了太阳从东山顶的丰收峰上升起又从西山顶的天王峰上落下的时候, 每年的 这个时候这户彝族人家的三兄弟就到了收获自家地里的稻米的时候了, 在这个本该高兴地时 候。平时在山上树木上自由歌唱的云雀哑了嗓子, 湖里的鱼和青蛙都躲到了湖底的岩石下面, 蟒蛇躲进了深山里的岩洞里, 家里的花狗在莫名的狂吠, 就连前几天还在地里吃着稻子的老 鼠也都不知道藏到哪里去了。三兄弟知道又到了天王派天将来破坏他们庄稼的时候了。原来 在这座山顶的云端上生活着天王一家。天王是这里一切的主宰, 他向这里的一切生灵宣布这 里的一切都是他的, 一切都得听他的, 否则就会受到惩罚。云雀告诉三兄弟, 天王一家生活 在云端, 除了天王夫妇外他们还有一个美丽的女儿。天王夫妇视他们的女儿为掌上明珠, 但 是天王的女儿从来不因为自己是天王的女儿就作威作福, 她对山上的动物都很好, 也很温柔 贤惠。

每年天将来破坏后, 三兄弟只剩了一点够自己吃的稻谷, 有时候连来年下种的种子都没 有留下, 他们只好忍饥挨饿来度过这一年。每年在看到稻谷成熟, 丰收在望的时候天王都会 再次把他们推入绝境, 他们又过着一无所有, 难以温饱的生活。他们的能力有限, 又不足以 和天王对抗, 只能过着忍气吞声的生活, 他们年年都会想一些办法, 但是最后都以失败而告 终。人与神的力量对抗在目前来看还是处于非常劣势的地位。天将每年都会在这个时候稻田 里的土拱翻, 将稻田的谷子全部施法术抢走。他们兄弟三人只能靠之前偷偷收获的一点稻米 生活。

三兄弟对天王的仇恨就像山下湖里的水一样多, 就像山上的树木一样多, 就像山顶的云 一样多。他们每年都在想办法对抗天王但是每年都以失败而告终。今年三兄弟在等着收获稻 谷的时候见到了云雀, 云雀见到三兄弟对他们打招呼说: “老邻居们，你们怎么又愁眉苦脸 的呢? 是不是天王又派天将来破坏你们的庄稼了？” 大哥说：“这个万恶的天王，我有一天 一定要把他杀死, 叫他在也不能来祸害我们。” 二哥说: “这个坏蛋天王, 我一定要把它狠 狠地打一顿, 叫他也体会到我们的痛苦。” 老三说: “我一定要想办法和天王有所联系, 和 他达成协议, 让我们能够和睦相处。” 云雀和他们一块出主意看怎么能够把天将打败, 保住 今年的收成。云雀告诉他们原来天将有贪酒的毛病, 只要他们在天将来破坏庄稼的时候将几 坛杆杆酒放在地头，天将就会先喝酒后施展法术，等到天将喝醉，他们就可以将天将擒住。 他们就把家里的几坛杆杆酒全部拿出来摆到了地头上。

这一天忽然狂风大作, 湖里掀起了很大的浪, 山上的树木也被吹得东倒西歪, 乌云笼罩 了整个天地。漂泼大雨从早上开始下了起来，三兄弟知道是天将来了。天将到了三兄弟的稻 田里, 刚要准备施展法术时看见了地头上摆的几个酒坛子, 就打开一个酒坛子尝了尝, 发现 味道香醇无比。贪酒的天将怎么能阻挡美酒的诱惑, 就把地头上的酒坛子全部喝光了, 天将 喝的晕头撞向时三个兄弟突然从旁边草从里闯出, 手拿绳索把天将捆了个严严实实。天将就 醉醺醺的被抬到了三兄弟的屋里。三兄弟对天将早就恨之入骨, 大哥拿出了一把刀, 想要把 天将杀了。二哥拿出来一根棍子, 要痛打天将一顿。三弟给天将端来一杯水, 叫天将先醒过 酒问清楚再打再杀。天将醒来将自己被困在柱子上, 又见到大哥二哥拿的刀子和棍子早就吓 的魂飞魄散, 急忙求饶, 他说他也是被迫无奈才来祸害三兄弟的, 都是奉天王的旨意才来破 
坏庄稼的。三弟问他：“天王为什么要来破坏他们的庄稼？” 天将告诉三兄弟：天王是这里 的唯一的大神, 他不想看到三兄弟通过辛勤劳作收获到很多的稻谷而和山上的各种动物们和 睦相处, 这会大大的影响天王在这里的地位。因为三兄弟种植稻米后小动物们都会知道有三 兄弟通过自己的劳动过上了幸福的生活，而天王的神圣与伟大就会大大的削弱。天王一直在 考虑用什么办法来铲除这些不在信奉他的生灵, 想要把三兄弟和山上的动物们全部除去, 作 为对他们的惩罚。天王打算开决天河, 把这里所有的生物都淹死。”三个兄弟忙问怎么才能 躲避洪水。天将叫大哥在山脚下用锡盖一座房子, 把房子修得结结实实, 不要有一点透水的 的地方; 叫二哥在山坡上修一座铁房子, 也要修得密不透风; 叫三弟在山顶上修一座泡木房 子, 要修的结实一点。三兄弟问到对策后就把天将给放了。他们都来不及收拾地里的庄稼就 忙着修自己的房子去了, 倒是耗子、青蛙和花狗等小动物们在稻田里似乎无忧无虑的玩要。自 放走天王走后整整十三个日日夜夜，三兄弟也修好了自己的屋子。

从第十四天起，天上下起了大雨，刮起了大风，湖水猛涨，那大雨就像从天上而来的瀑 布一样, 直接从天上落到了山上。大雨一直在下, 湖水一直再涨, 天河的水从山脚下一直涨 到了山顶, 大哥二哥因为听了天将的话把自己牢牢锁在锡与铁制造的屋子里而活活窒息而死 去了。山上的小动物随着洪水的上涨也在不断的上涨, 由于之前向大哥二哥求救而因为害怕 洪水冲进屋子没有收留他们, 他们只好上山顶去找三弟。三弟大方的收留了他们, 他们有鸟 类, 有蛙类, 有兽类等各种小动物。天河的水在到达山顶时开始慢慢退去, 好久不见的太阳 也从丰收峰上升起。这时的人间只剩了老三一个人，还有就是一些动物朋友。

在天河的洪水退去后，老三去找了大哥二哥的锡房子和铁房子，发现他的大哥和二哥和 他们的房子都被洪水冲走了，好多的树木也被冲走了，他们的稻田也变成了光秃秃的土地。 他感到非常伤心，小动物们也很难过。自从这次天河决口以后天河的水不仅冲毁了人间的一 切, 也冲破了天与地, 神与人的界限。天王以为天河的水会把人类以及动物灭绝, 也就无所 谓使天和地、神与人的界限被冲破。到时候这里的一切都是天王的，都是神的。

这一切的变化是在耗子无意中闯入天王的家后发现的。原来一场大洪水给他们带来了灾 难也带来了新的变化与希望。耗子把这个消息告诉了老三。老三和他的动物伙伴们商量怎么 重建家园。

天王收回天河的水后以为三兄弟和其他动物都已经被淹死了, 很是高兴。他兴奋的拨开 云雾却发现山顶上还有一座房子, 而且还看见了老三他们。他还听见了在老三房子顶上鸹鸹 叫着的乌鸦。天神慌了, 急忙叫妻子拿天书过来查看是怎么回事。却发现天书已经被耗子吃 的只剩一堆烂渣了。天王气急败坏, 亲自来追杀耗子, 耗子疾跑慢跑的把天王引到了深山中, 这时早已在山中埋伏的蟒蛇出洞, 咬伤了天王的脚, 天王痛的哇哇大叫, 只好回到天宫去休 养。天王叫来了他的天兵天将却没有一个能够治好他的脚伤。这时云雀告诉天王青蛙能够治 好天王的脚伤。天王的妻子就请来了青蛙。青蛙是个饱学之士, 瞪着自己的大眼睛显得对这 个世界上的一切都充满了兴趣。他告诉天王, 除非天王把自己温柔可爱的女儿嫁给老三, 他 才会答应给天王治病。天王心想现在只好先答应青蛙的要求等治好伤后再作打算。就这样, 青蛙一边叫老三和天王的女儿结婚, 一边假装给天王治着病。等到老三和天王的女儿的婚事 完成。青蛙就悄无声迹的失踪了, 天王派了所有的人去找都没有找见, 原来青蛙知道自己治 不好天王的病又想帮老三娶到天王的女儿, 就和云雀商量好通过这样的方式促成老三的婚事。 事成之后, 青蛙离开平时生活的湖里躲到了山中的岩石里（就这样青蛙成了两栖动物）, 躲 过了天王及其手下的的寻找。天王抓不到青蛙，伤口越来越深，不久就一命鸣呼了。

老三娶了天王的女儿后, 天王夫人就带领天界的天兵天将离开了他们, 到了一个谁也找 不到的地方。天王的女儿每年到这时候都会想念天界的母亲和死去的父亲。

老三夫妇和他们的动物朋友们在考虑怎么恢复以前的幸福生活。大洪水把所有的稻谷都 冲走了, 他们又找不出其他能够种植的农作物, 大家都在山上各处不停地寻找种子时喜鹊发 现了花狗的尾巴上还有三粒谷子。春天老三夫妇把这三粒种子中到地里, 秋天收获了三个稻 穗。第二年又把三个稻穗的谷子全部下种得到了更多的谷子。到第三年太阳又从丰收峰上升 
起的时候, 老三夫妇收获了千斤稻谷。动物们也分得了各自的那一部分。老三夫妇也繁衍了 更多的彝人后代，老三夫妇后来离开了人世，但是他们却留给了后人一个过年的节日。每年 到了太阳从丰收峰上升起的时候, 彝人收获了田里的稻谷就会祭祀为了获得丰收而死去的祖 先, 也会祭祀那些帮助三兄弟的天将还有那些动物朋友们。这个节日既是在庆祝丰收也是在 缅怀先人。这个节日也成为彝族太阳历中一年的起始, 寓意万象更新, 年年丰收。这个节日, 在彝语里叫做 “库识”，在彝族社会流传了很久很久。[5]

3.2 彝族年的仪式

彝族年，凉山彝语叫 “库识” 即 “过年”。“年” 彝语把它叫做 “库”，其义为: 转、 回、回转、回归、循环。彝族年根据彝族传统的十月太阳历确定，一般在每年秋末冬初的十 一月中旬进行，一般在马日，民间常说 “蛇日觉罗基，马日把猪杀”。过年时间三天，加上 之前准备的时间，大概有一周。

1. 过年前两三天：上山打柴、割草和砍竹子，做豆腐、打米面、辣椒面等。

2. 过年前一天：搞清洁卫生。洗洁厨具、餐具、衣物等, 磨好刀具, 备水。新年前夜也 叫 “觉罗基”。开展一些全家团聚的活动，祈求来年人丁兴旺。

3. 第一天：第一天叫 “库识”，是新年的意思。主要内容是祭祖。早起，烧开水，给杆 杆酒加水, 烧石头, 把米、菾面、酒、碗、酒杯放在留给祖魂的位置旁边。天亮, 在屋外烧 烟火通知祖魂, 屋内把烧红石头放在水里, 围绕着墙边反时针转, 然后倒在门外, 表示屋内 清洁的。栓好狗猫。青少年杀猪。完毕后主人家吃年饭, 饭后, 把放在祖魂位前的饭菜收起 来, 全家每人尝一口后放好, 不能吃掉。放狗和猫, 小孩出屋拜年, 大人在家迎接来拜年的 队伍，拜年队伍在每家唱过年歌，过年歌一般分为三段，备年、迎祖和祝福。

4. 第二天：第二天叫 “朵博”，意为 “月首”。主要是 “社日” 仪式，互相拜年。留下 到岳父母家拜年的猪肉, (一般是猪身的上半截一半)把砍猪肉砍成条块, 在火炉上烟熏, 屋外 开展赛歌、摔跤等各种文体活动。

5. 第三天：第三天叫 “阿普机”，意为 “送祖灵”。做冻肉，男孩们带猪脚，女孩带条 肉, 大人带上酒饭或荞粑等, 在屋外做敬鹰仪式。在竹竿尖上串一点肉等食物, 酒酒, 插在 地上后等老鹰来吃, 大人小孩一起分食带来肉和其他食物。晚饭。先敬祖魂, 然后祖魂的饭 菜收好后, 全家人才能用餐。晚上家人不得外宿, 即使出去玩, 必须得鸡叫前返回, 因为祖 魂要清点人数。当晚第一声鸡叫时, 把第一天和第三天敬祖魂的饭菜加热, 端到祖魂前, 让 祖魂吃饱上路。送走祖魂后, 祖魂吃过的饭菜家人尝一口就行了, 留做早餐。 $[6,7,8]$

\section{4. 后现代视野中彝族新年神话的社会价值}

\section{1 新年神话是彝族社会重要的的精神根源和灵魂家园}

彝族新年的神话传说、仪式与传统习俗共同构成了彝族新年神话的内涵。神话的思维及 其仪式支撑着人们面对死亡和虚无时的恐惧与丰收和新生时的喜悦, 当死亡恐惧或者丰收喜 悦来临时，不致毫无准备而惊慌失措。神话叙述的是彝人对新年的来历以及过新年的意义， 而具体的仪式与传统民俗却是对神话传说的那种新年的神话精神的具体实践, 在这种具体实 践中再次重温神话传说的神圣精神，而神话传说中的神话精神又不断的提醒人们具体的新年 仪式与传统习俗在操作时应该怀有的内心感受。在彝族新年仪式中最重要的就是对祖先的崇 拜与敬重。在家人食用食物之前都要通过各种方式祭祀祖先, 具体的活动背后都有祖先的影 子。节日仪式即使人们体会到了丰收的喜悦又使这种丰收具有了神圣的意义。彝族新年神话 对彝人勤劳勇敢、敬畏自然、崇拜祖先、热爱和平的民族精神有清晰的表述，几千年来彝人 在新年节日中通过新年的仪式以及民俗不断的重温这种精神并成为民族精神的一部分。

\section{2 新年神话中蕴含着大量生存的智慧}

新年神话体现出彝人取得丰收所付出的辛勤劳动与祖先为生存与获的丰收所付出的生命 的代价。神话中还体现出对大自然以及动物们的感激。在具体的新年仪式中砍年猪的具体步 骤中也体现出对自然的朴素理解, 分别取出猪的器官通过猪的器官的健康与否判断大自然的 
具体变化以及来年丰收情况。新年神话所蕴含的包容性能够让我们接纳所有的同类。神话中 的老三和公主正是在小动物们的帮助下才战胜了天王, 实现了和平与稳定的生活。我们需要 令我们富有同情心的神话, 而这在推崇实用、理性的现代社会是严重贵缺的。神话中正是老 三对天将处境的理解与同情才能够幸免于难。人们需要新的精神纬度的新年神话, 让人们不 急功近利, 不妄自尊大与自私自利, 体验到一种新的超验体验。在新年的时候, 平时负担繁 重的工作的人们放下各自的工作与家人和亲戚邻居们在一起, 使人们不致在金钱与物欲的追 求中迷失了本性。我们需要敬畏新年神话, 而不仅视其为一种可利用与长存的节日。

\section{3 新年神话包含非物质文化遗产保护的理念}

后现代视野的新年神话包含了非遗保护中的活态性保护、本土性保护与整体保护原则。 彝族非物质文化遗产, 是始于原始狩猎文明, 继而发展到农牧文明、农耕文明最终在现代化 的农业生产条件下，在生产生活中产生的与彝族民众息息相关的、代代相传的民俗活动、表 演艺术等文化情境和综合性文化系统。后现代的神话观对保护作为彝族非物质文化遗产的彝 族年有很好的理论指导意义, 对重新认识与更好的传承与保护彝族年有现实意义。[9]

\section{致谢}

感谢西南民族大学胡静老师对文章提出中肯的修改建议, 感谢西南民族大学刘军同学对 论文英语摘要的翻译意见。

\section{References}

[1]. Ye Shuxian, houxiandai de shenhua guan- jianping shenhua jianshi (View on myth in post-modern time-on A Short History of Myth). zhongguo bijiao wenxue (Comparative Literature in China). Vol. 66 (2005) No. 1, p. 46-57.

[2]. Karen Armstrong, A Short History of Myth [M] . Edinburgh: Canongate,2005.

[3]. Ye Shuxian.zhongguo shenhuaxue bainian huimou (A review of the Chinese mythology in lately 100 years). Xueshu jiaoliu（Academic Exchange）. Vol. 130 (2005) No. 1, p. 154-164.

[4]. Jack Goody .Myth, Ritual and Oral. [M] . Cambridge University Press .2010.

[5]. Xue Li. yizunian de chuanshuo(A myth about Yi's new year) . [M].zhonghua minsu yuanliu jicheng -jieri suishi juan(The beginning of Chinese myths-festival),Gansu People Press, 1994, p. $629-630$.

[6]. Liangshan yizu zizhizhou renmin zhengfu (The government of Liangshan Yi people autonomous county) , [M],zhongguo yiwen dianji yicong 2(The Chinese translations of the classics of Yi language 2),Sichuan National Press,2006,p. 262-273.

[7]. Jiejue Yihong, Liangshan yizunian de baoliu yu liubian(keep and change of Liangshan Yi' New Year), [N],jiaoke xinbao-jiaoyu keyan ,2010(7).

[8]. Zhu Wenxu, gaishuo yizu nian(A Introduction to Yi's new year), [EB/OL], http://www.yizuren.com/plus/view.php?aid=1567, yizuren net,2004-11-24.

[9]. Jia YinZhong. zhongguo yizu fei-wuzhi wenhua yichan gailun ( A Introduction to the Intangible Cultural Heritage of China's Yi People).Beijing:minzu Press(National press).2014 . p. 58-60. 